\title{
Spiritual and moral development of the individual in Russia in the XXI century
}

\author{
Dina Kazantseva ${ }^{1 *}$, Elena Tkach $^{2}$, Lyudmila Shukshina ${ }^{3}$, Svetlana Taisaeva ${ }^{3}$, and Elena \\ Dolgova ${ }^{3}$ \\ ${ }^{1}$ Southern Federal University, 344006, Bolshaya Sadovaya st., 105/42, Rostov-on-Don, Russia \\ ${ }^{2}$ Pacific National University, 680013, Karl Marx Street, 68, Khabarovsk, Russia \\ ${ }^{3}$ Plekhanov Russian University of Economics, 117997, Stremyanny lane st. 36, Moscow, Russia
}

\begin{abstract}
Nowadays the spiritual and moral tendencies of Russian society are due to the opposition of the spiritual and moral foundations of the traditional mentality to the intrusion of Western non-traditional mentality values. As a result of the imbalance, the spiritual image of Russian society, as well as the spiritual and moral image of the individual, his worldview is transformed. The representatives of educational institutes, state and municipal authorities, the media, who are most closely related to this problem, discuss the issues of the spiritual and moral development of a personality, emphasizing their importance for the civilizational future of Russia. An expert assessment of spirituality and morality provides the opportunity to determine the possible ways of overcoming the crisis. In this regard, an expert survey as a sociological study was conducted in three stages: in 2009 it was a pilot study to clarify the toolkit, as well as in 2010 and 2019 there were some surveys of the representatives of three activity areas. The research was based on such approaches as personal, activity, systemic and subjective. The results were the consideration of the experts' understanding of the content of the concepts "spirituality", "morality", "spiritual and moral development", the determination of the level of morality and spirituality of Russian society, the conditions that cause its decline, and the conditions, resulting in its development. An expert survey made it possible to reveal a low level of the spiritual and moral development of the society, distortion of the spiritual and moral baselines for the development.
\end{abstract}

\section{Introduction}

A modern society is characterized by the presence of conflicting trends. A return to traditions is declared, but there is no appeal to them. On the contrary, Western values are being introduced more and more often. As a result of the imbalance in the psycho-protective fundamentals of the mentality in Russian society, there is a lack of the life principles and rules, the guidelines for the life meaning, the correct and constructive social behavior, and many others which are consciously accepted by the majority of citizens. In this situation, a competent state policy is needed, aimed at supporting the traditional mentality, the formation of a highly moral, responsible, spiritual, proactive and competent citizen of Russia.

* Corresponding author: $\underline{\text { iren3d@mail.ru }}$ 
All of the above makes the study of the spiritual and moral state of Russian society particularly important and relevant, determined by the fact that the political, socio-economic transformations that have taken place in Russia have significantly transformed the spiritual image of Russian society, changed the moral and spiritual image of Russians, their worldview. The analysis of the ongoing implementation of the spiritual and moral development of a young individual's personality, moral values in modern Russia, and definite ways of the development is possible on the basis of collecting data from the experts, namely from the representatives of educational institutes, as well as state and municipal authorities, the media, who are most closely in contact with this problem.

The discussion on the issues of spirituality and the spiritual and moral development of an individual has recently been increasingly carried out at all levels: the state of modern Russian society, the crisis of spirituality, which has engulfed all aspects of the human life, and many others, are being analyzed. Especially significant are the studies that determine the anthropological foundations of the civilizational future of Russia by L.S. Perepelkina [1] and Yu.M. Reznik [2], the mentality of a Russian and the specific features of modal models of the social behavior manifested in every sphere of Russian society, for example, in social one by A.V. Lubsky [3], in political one by R.A. Lubsky, V.P. Voitenko and others [4], in economic one by E. Titova [5], in the spiritual and moral foundations of the national way of the Russian man by V.V. Babashkin [6].

The spiritual nature of man is investigated by the experts in the works of the best philosophers and psychologists of the world, Yu.V. Verba [7], it is seen through the transformational processes of an individual's spiritual and moral potential and his selfrealization in Russia, D.B. Kazantseva [8], as well as through the formation of the spiritual and moral foundation of Russian civil identity, E.K. Klimova, T.E. Chernysheva and others [9].

Directly worldview values and meanings of the individual, the essence, determinants, mechanisms of the development and relationship with morality, significance for creating a modern scientific picture of the world, are well manifested in the works of A.R. Bulatova [10], O. Yu. Glukhova [11], A.V. Gushchina [12], E.Yu. Pochtareva [13], L. Sagiv, S. Roccas, J. Cieciuch, S.H. Schwartz [14], M.S. Yanitsky [15], and many others.

\section{Materials and methods}

To study the spiritual and moral development of an individual in modern Russia, an expert survey as a sociological study was conducted in order to clarify the foundations of this process, namely, understanding the essence of the concepts of "spirituality", "morality", "moral and spiritual development" carried out among the representatives of the media, state and municipal authorities, university lecturers and school teachers in 2009, 2010 and 2019. The need to identify the definition unambiguity of the essence of these concepts was dictated by the importance of creating a unified basis for the planned actions in transforming Russia.

Methods and selected tools: expert survey tools; expert survey questionnaires; instruments for fixing information obtained in the course of sociological research. Data collection methodology: the primary information base was formed on the basis of field research data. The research was based on personal, activity, systemic and subjective approaches. The selection of the experts was carried out by the snowball method, which is designed to find hard-to-reach respondents.

At the first stage, in November, 2009, a pilot sociological survey was carried out to refine the research instruments. A research plan, including the definition of the general population and the design of the sample; draft questionnaire of the experts was formed. The main objectives of the research: to define the concepts of "spirituality", "morality", "moral and spiritual development" through expert assessments; approbation and testing of the 
methodology and tools of the pilot study; the development of recommendations for adjusting the design of the sample and the questionnaire based on the results obtained. In total, 25 people were interviewed using this method.

At the second stage of the study, in February, 2010, a survey of 30 experts, the representatives of three activity areas, was carried out; there were 10 people out of state and municipal administration, 10 people out of higher education, and 10 people out of the media. In total, using this method, 30 people aged 44-62 years were interviewed. There were 18 male and 12 female. The preparation and conduct of the expert survey included: the identification of a potential circle of the experts, the formation of their lists, and the development of the questionnaire forms.

The main objectives of the research: determination of the content of the concepts "spirituality", "morality", "moral and spiritual development", through the expert assessments; determination of the level of the spiritual and moral state of Russian society on the basis of the survey; identification of the indicators that cause the spiritual and moral decline of Russian society; identifying the conditions conducive to the spiritual and moral development of Russian society.

Thanks to a detailed analysis of these researches, namely the expert survey of the first stage, some problems in the methodology and tools of the survey were identified. Therefore, at the second stage of the research, the following points were corrected:

1. the question wording, namely, the questions containing scientific terminology were corrected in the questionnaires; changed ambiguous and leading questions that could mislead the respondent;

2. the answer options (reaction codes) were corrected, a number of questions on the sufficiency of the codes to display the reaction were revised; the differentiation of reaction codes for a number of questions with an overly detailed list was also revised;

3. the structure of the questionnaire was adjusted, the questions aimed at studying the role of the state in the formation of moral and spiritual values of the young generation and the state mechanism for the formation of these values were added;

4. the methods of selection and a number of the experts were formed.

The third stage of the expert survey was conducted in March, 2019. It completely used the same content and stages as the 2010 survey. The results and conclusions obtained are presented in the study.

\section{Result}

During the first stage of the research in November, 2009, an expert survey was prepared and conducted, where the absolute majority of the experts (96\%) declared a sharp decline in the level of spirituality in our society (Figure 1).

At the same time, the experts unanimously named the Americanization of Russian society $(84 \%)$, a low social level $(72 \%)$, the media that destroy spirituality and morality with their advertising (52\%), indifference to absolute values as the main reasons of this process. (44\%), etc. (Figure 2).

Clarification of basic concepts understanding showed that when the experts were asked what spirituality is, the most ones said (Figure 3 ) that it is morality $(68 \%)$, the inner world of a person (64\%), empathy, kindness to other people (40\%), etc. 


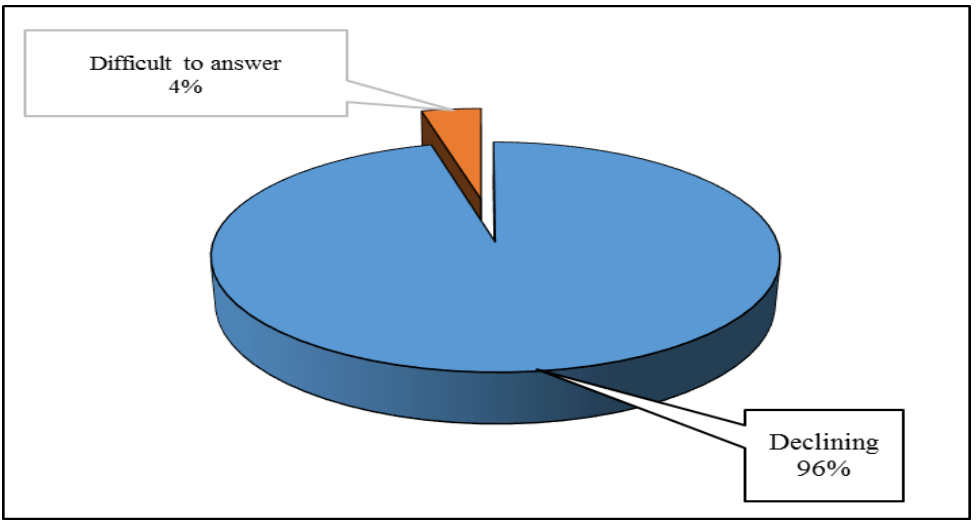

Fig. 1. Expert assessment of the level of spirituality of a modern society.

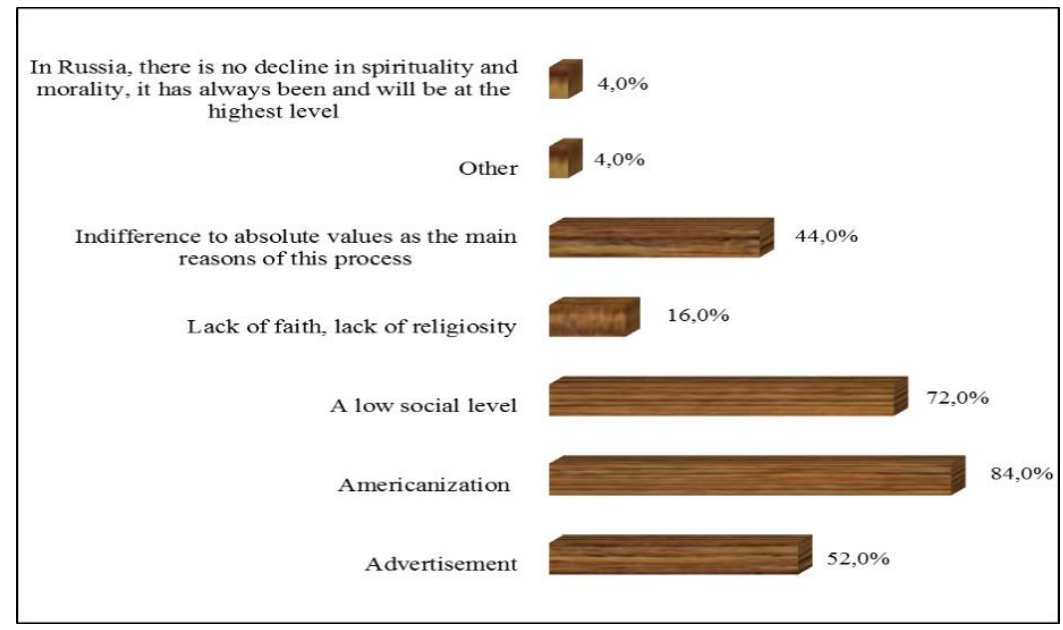

Fig. 2. The main reasons for the decline of spirituality and morality in a modern society.

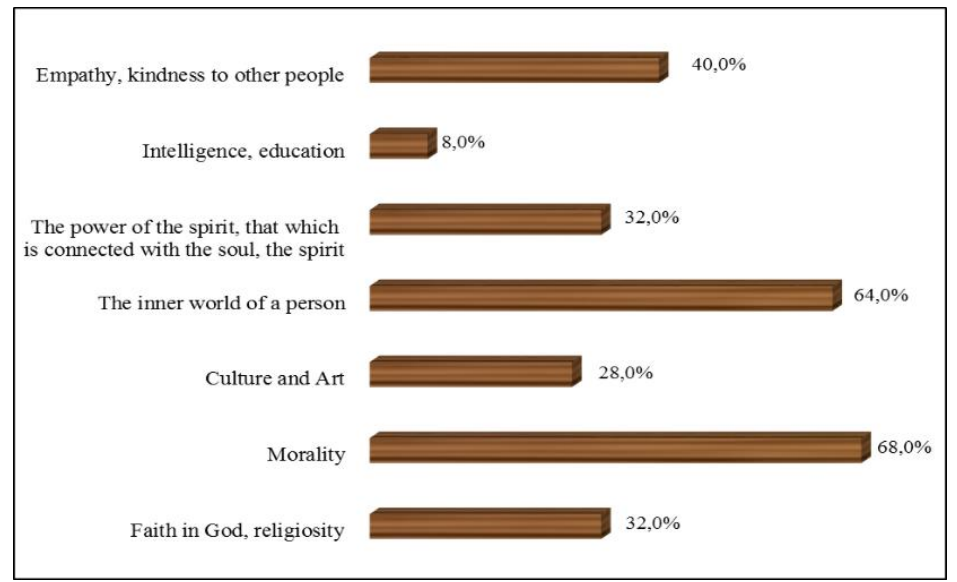

Fig. 3. The experts' answers to the question "What do you mean by the concept "spirituality"?"

Answering the question of what morality is (Figure 4), the experts noted that these are ethical norms and rules of behavior (64\%), internal spiritual rules on which a person relies 
$(60 \%)$, the value structure of consciousness $(56 \%)$, etc. On an additional question, all the experts declared that morality and spirituality are almost the same things.

It can be stated that the representatives of the authorities, the media, and the education system combine the concepts of morality and spirituality. Thus, $60 \%$ of the experts identified morality with inner spiritual qualities (Figure 3), despite the fact that, in its essence, as noted in a number of studies by D.B. Kazantseva [16], spirituality is the basis of morality, not being morality itself.

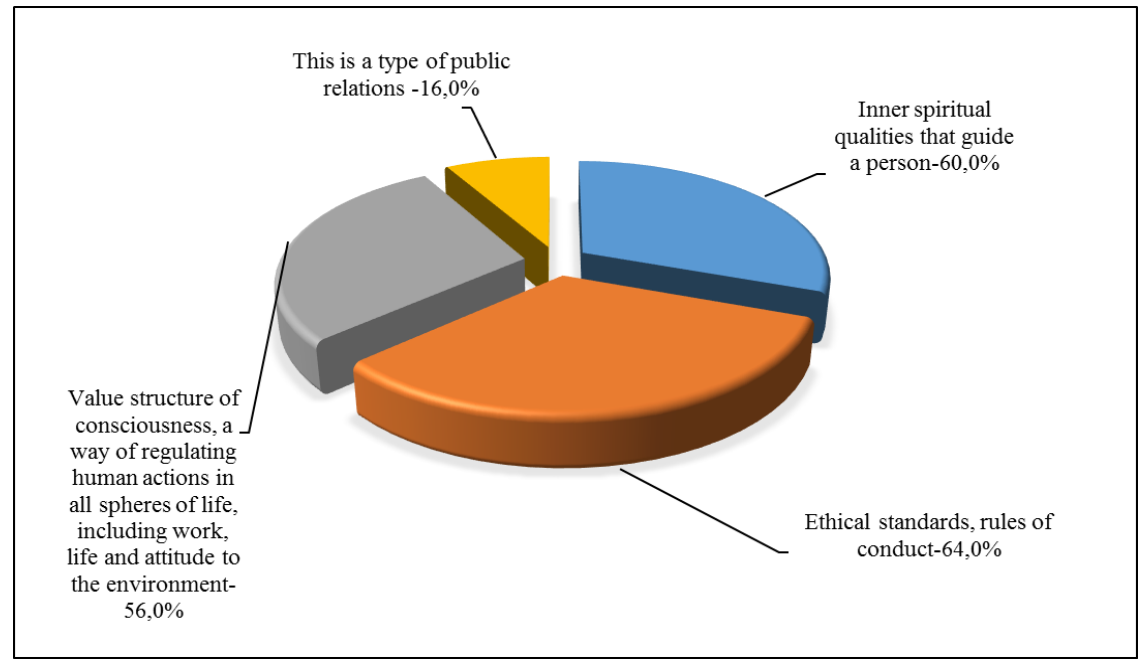

Fig. 4. The experts' answers to the question "What do you mean by the concept "morality"?"

During the survey (Figure 5), the experts spoke about the need for the spiritual and moral development through moral education and enculturation (84\%), media censorship (76\%), improving people's welfare (72\%), solving social problems $(64 \%)$ and problems in education $(60 \%)$, strengthening the family institution $(52 \%)$, etc.

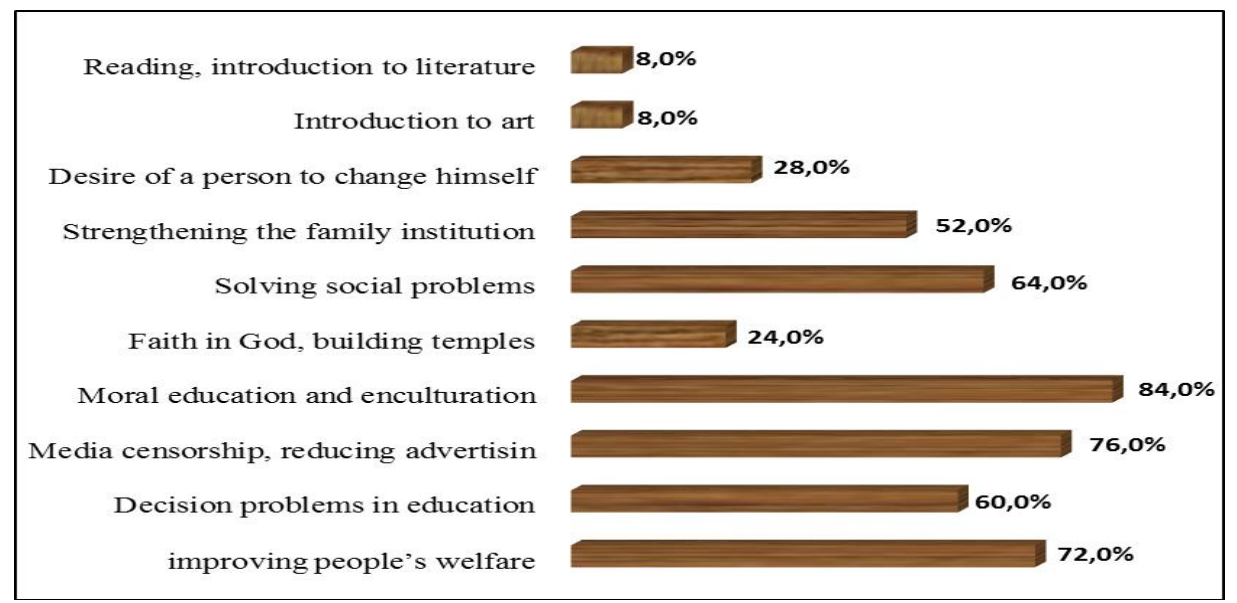

Fig. 5. Features of the spiritual and moral development of a modern society.

At the same time, it was men (Table 1) who noted the priority of young generation education $(87.5 \%)$, the role of the family institution $(75 \%)$, while women more indicated the need to improve people's welfare $(88.2 \%)$ than on strengthening the family institution 
(41.2\%), on the importance of moral education and enculturation (82.4\%), as well as media censorship and advertisement reducing (82.4\%).

Table 1. Expert assessment of the features of the spiritual and moral development of a modern society, depending on gender, in $\%$.

\begin{tabular}{|c|c|c|c|}
\hline \multirow{2}{*}{} & \multicolumn{2}{|c|}{ Your gender } \\
\cline { 3 - 4 } & Improving the material standard of \\
living & 37.5 & 88.2 \\
\cline { 2 - 4 } & Solving problems in education & 25 & 76.5 \\
\cline { 2 - 4 } & $\begin{array}{c}\text { Media censorship, reduced } \\
\text { advertising }\end{array}$ & 62.5 & 82.4 \\
\cline { 2 - 4 } & Moral education, introduction to \\
culture & 87.5 & 82.4 \\
\hline $\begin{array}{c}\text { What could } \\
\text { contribute to } \\
\text { the spiritual } \\
\text { and moral } \\
\text { development } \\
\text { of the } \\
\text { country's } \\
\text { population }\end{array}$ & Faith in God, building temples & 37.5 & 17.6 \\
\cline { 2 - 4 } & Solving social problems & 62.5 & 64.7 \\
\cline { 2 - 4 } & Strengthening the family institution & 75 & 41.2 \\
\cline { 2 - 4 } & Desire of a person to change himself & 37.5 & 23.5 \\
\cline { 2 - 4 } & Enculturation to art & & 11.8 \\
\cline { 2 - 4 } & Reading, enculturation to literature & & 11.8 \\
\hline
\end{tabular}

The results indicate that the experts, stating the crisis state of the society, do not have an unambiguous position on improving the situation. This is due to many reasons, one of which is the peculiarity of the interpretation of such key concepts as "morality" and "spirituality", the lack of a clear scientific, public and state interpretation of this issue. Hence follows a variety of interpretations of the concept "spiritual and moral development of the individual" and, as a consequence, of the stages, content, mechanisms of the personal and social development.

So, the experts' answers to the question "What do you mean by the concept of "spiritual and moral development"?" were as follows: education of moral and ethical qualities in oneself and the activity in accordance with them; education of a law-abiding citizen; the activity of a person in his life on the basis of conscience; spirituality of the individual and the development of spiritual qualities; the rules of behavior adopted in the society and the development of a person's spiritual forces; the life according to the foundations of the society; mastering the highest human values and promoting them in his life; development of a person's internal forces, his potential; the formation of a harmonious personality; the formation of a culture of personality; ethics and aesthetics of human relations; the life in accordance with his religious belief, etc.

The comparative results of the expert study of the second stage, carried out in February, 2010, and the expert study of the third stage, carried out in March, 2019, show that the absolute majority of the experts declared the sufficiency of the problems in the field of the spiritual and moral development of Russian society.

At the same time, the spiritual and moral development and personal improvement are defined by them as a process of forming new value orientations. Appealing then to the concept of "spirituality" as to the highest value they build a logical connection between spirituality and morality, the inner world of man, culture and art, strength of mind and soul (Figure 6,7). Some experts equate the concept of morality and spirituality, considering morality as internal spiritual qualities and ethical norms. The comparative characteristics of 
the 2010 and 2019 results show a slight difference in the vision of this problem over the past 9 years.

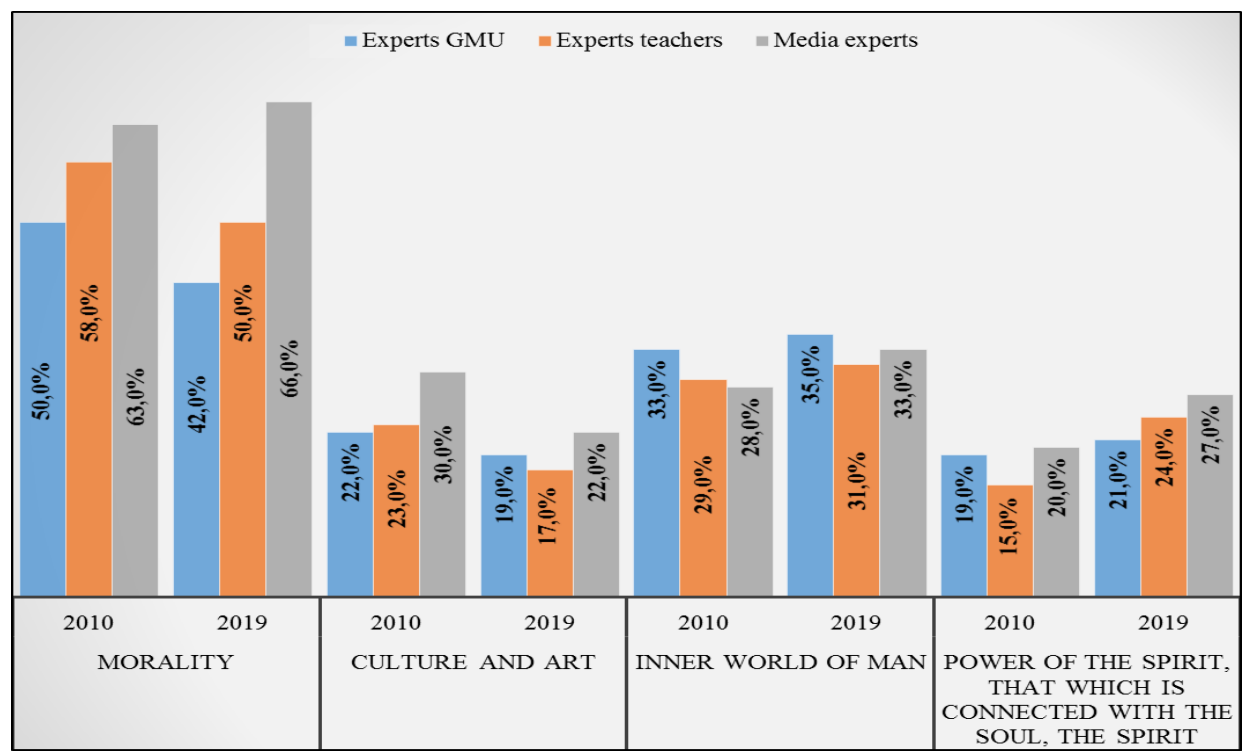

Fig. 6. Experts' understanding of spirituality.

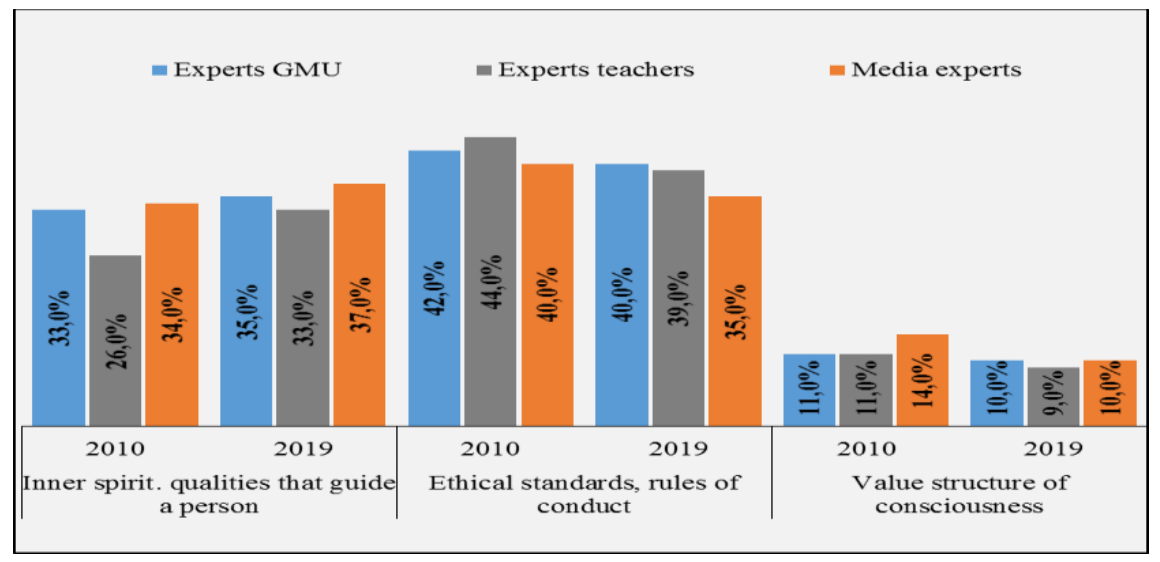

Fig. 7. Experts' understanding of morality.

The survey shows the experts' understanding of the unity of the content of morality and spirituality, closely intertwined and influencing each other. However, unfortunately, as in 2009 , their originality, the importance of the absence of reduction and transformation is not taken into account. All the experts adhered to a similar choice regarding the content of the concepts "spirituality" and "morality", paying less attention to the additional options of their possible meanings, such as "faith in God, religiosity", "intelligence, education", "kindness, helping other people", etc. So, for example, when answering the question "What do you mean by the concept "morality"?", they did not consider such additional options as: "this is a type of social relations", "these are restrictions and a system of prohibitions that are necessary for the society", etc.

When assessing the spiritual and moral state of Russian society, the respondents noted that there are many problems in this sphere (60-64\% in 2010 and $61-65 \%$ in 2019$)$, and the 
situation is catastrophic. The experts answered this question unambiguously, categorically and briefly (Figure 8 ). As the main reasons, they unanimously named the low social level of Russian society (51-56\% in 2010 and 52-55\% in 2019), indifference of the authorities (24$28 \%$ in 2010 and $30-33 \%$ in 2019), which destroy spirituality and morality (Figure 9, 10).

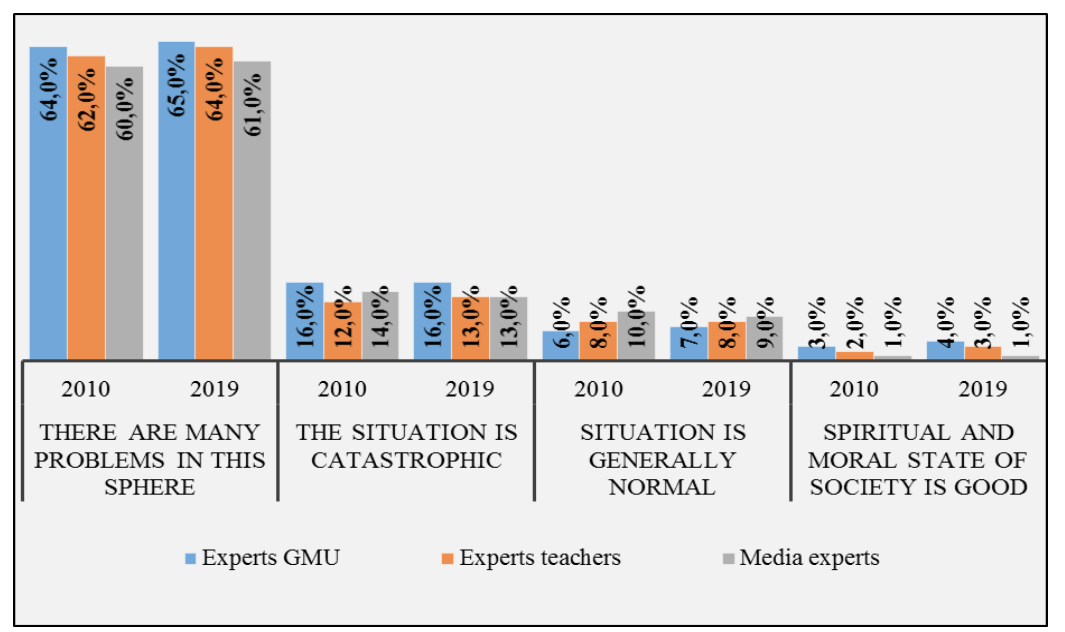

Fig. 8. Assessment of the spiritual and moral state of Russian society.

When analyzing the factors that cause the decline of spirituality and morality in the society, most researchers both in 2010 and in 2019 noted that all the indicators presented in this section of the questionnaire reflect different aspects of Russian reality and are the most important signs of the decline of the society: increasing the aggressive behavior of children, students and youth; criminalization among the teenages; the growth of juvenile delinquency; an increase in the number of divorces; an increase in the number of orphans and children left without parental care, unwanted children; an increase in the use of drugs, alcoholic beverages, beer and tobacco products; an increase in the frequency of the use of obscene and culturally low vocabulary by minors; open access for minors to Internet resources with pornography, harshness, violence, committing illegal acts; an increase in the number of teenage and youth extremist associations; an increase in the number of minors subject to addiction to video games, computer games, including online games on the Internet, games using game consoles, and games on mobile phones and smartphones.

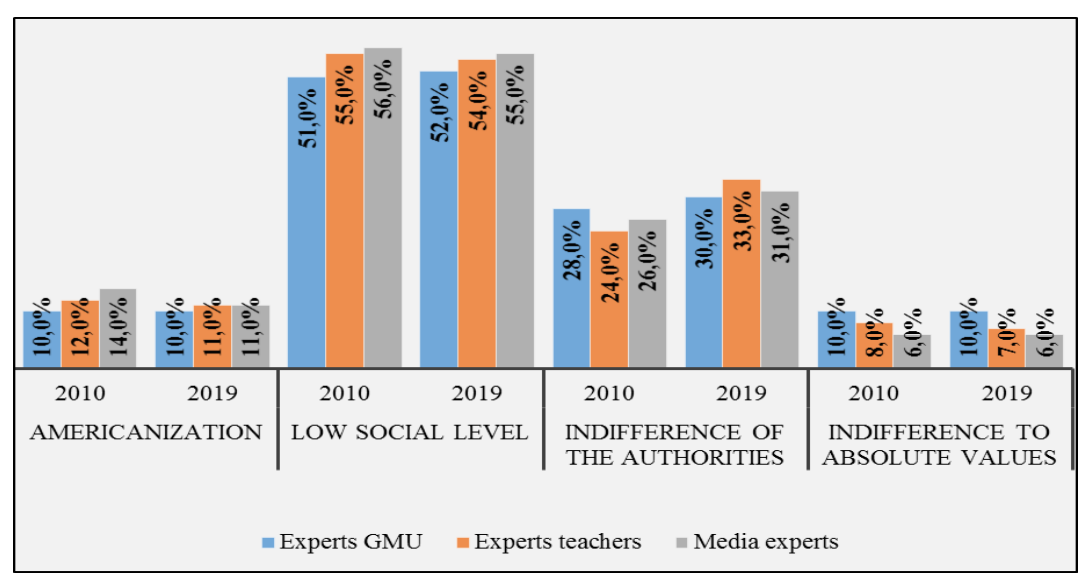

Fig. 9. Factors that cause the decline of spirituality and morality. 


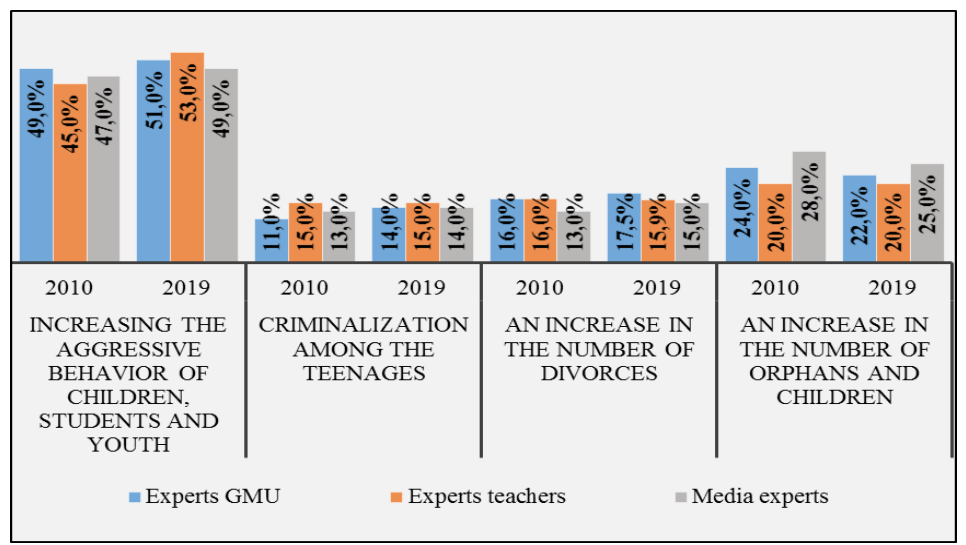

Fig. 10. Indicators of the spiritual and moral decline among the youth.

Due to the multitude of the factors that cause the decline of spirituality and morality, it is possible to change the current situation only at the level of the state regulation, therefore, according to the experts (61-75\% in 2010 and $45-55 \%$ in 2019), the support of the spiritual and moral revival of Russia should become the state power (Figure 11).

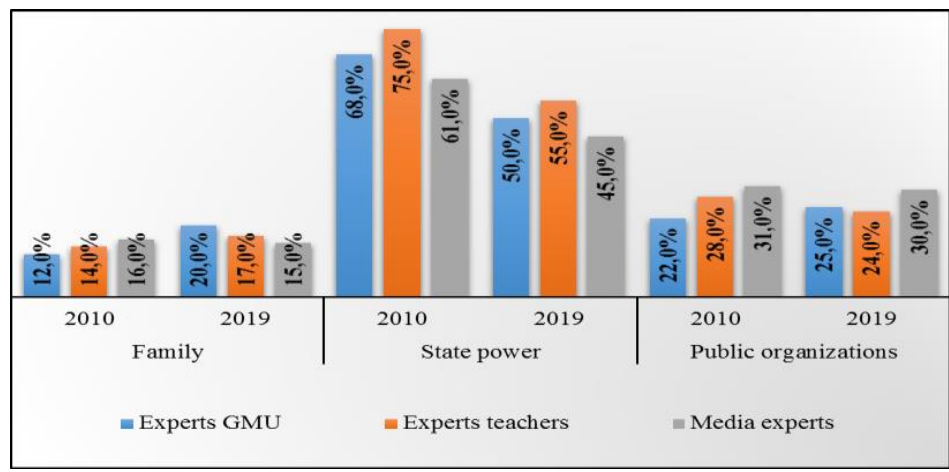

Fig. 11. Possibility of the spiritual and moral revival of Russian society.

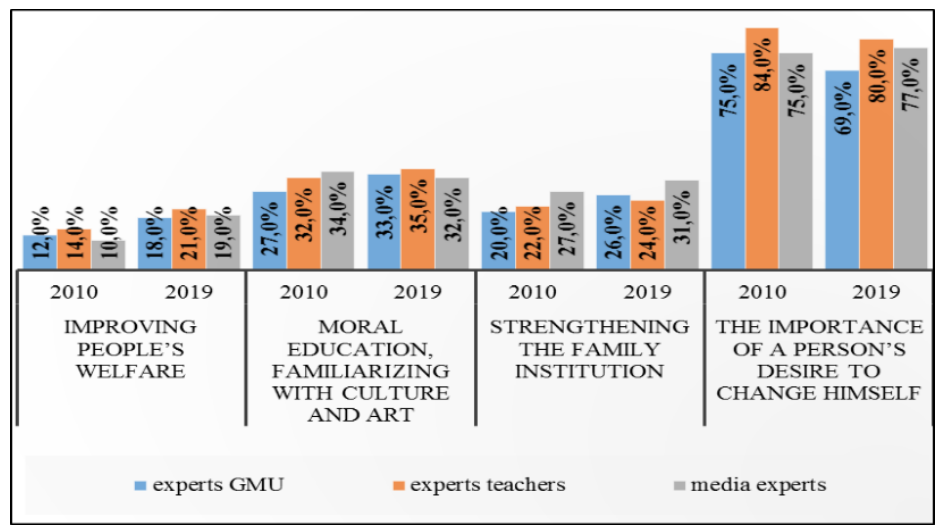

Fig. 12. Factors that cause the spiritual and moral development of the society.

Highlighting the factors that cause the spiritual and moral development of a modern Russian society, all experts noted the main thing - the importance of a person's desire to 
change himself (75-84\% in 2010 and $69-80 \%$ in 2019), and also added that at the same time moral education, familiarizing with culture and art, strengthening the family institution, improving people's welfare is necessary (Figure 12).

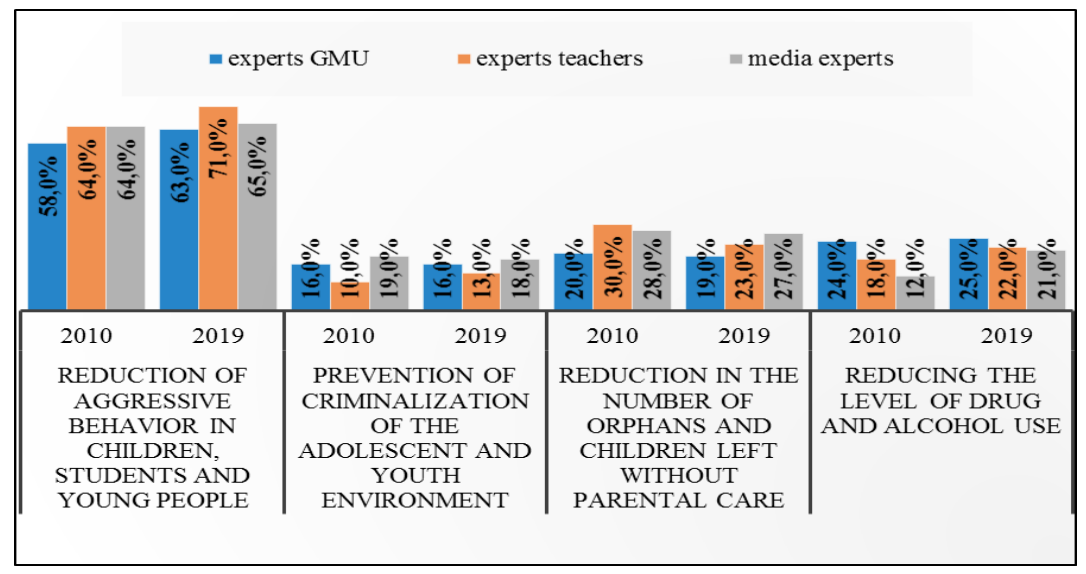

Fig. 13. Indicators of the spirituality and morality growth in the society.

The presented results of the expert survey, which determined the main indicators of the spirituality and morality growth in the society, do not need comments (Figure 13). Reducing the aggressiveness of young people, their criminalization, addictions, the implementation of the prevention of these changes are the most important sign of qualitative changes in Russian society.

\section{Discussion}

The expert survey at all three stages of the 2009, 2010, 2019 sociological research showed a continuing decline in the level of Russian society spirituality, the main reasons for which are: Americanization of Russian society, a low social level, destruction of spirituality and morality through the media. Domestic and foreign media, which are an important part of the socialization system of the individual in Russian society, form the public opinion, standards of life and consciousness, as well as assess people and events. At the same time, they, often ignoring the responsibility for the results of their activities, release substandard materials leading to a decrease in socialization due to the denial of the main foundations of the personality development, that is spirituality and morality.

The last decades, 2009-2019, the spiritual and moral state of Russian society and state regulation of this issue is assessed by the experts as catastrophic. The indifference of the authorities to absolute spiritual values, which are still declared, but are no longer implemented in practice, is stated. This contributes to the confrontation between traditional and introduced Western values, both in the souls of people and in the realities of Russian society. Thses contradictions result in the aggressive behavior of young people, an increase in juvenile delinquency, criminalization, various kinds of addiction, Internet addiction, an increase in the number of orphans and children left without parental care, and many others.

Among the experts, there was no unambiguous position on how to solve this problem. There is also no decision regarding the most acceptable option for Russian society to stop the decline of the spiritual and moral segment. At the same time, an expert assessment that integrates different aspects of reality already presupposes a solution to the problem of transforming the spiritual and moral level of an individual and the society. So, if the most important target indicators of the spiritual and moral degradation of a person become an 
increase in aggressiveness, criminalization, an increase in divorce and an increase in the number of orphans, then the most important target indicators of its spiritual and moral development can be a decrease in aggressiveness, prevention of criminalization, a decrease in the level of drug and alcohol use, reducing the number of children left without parents, etc.

To solve this problem, it is necessary to understand the essential content of the foundations of the spiritual and moral development that is spirituality and morality. The variety of the answers provided shows the inaccuracy of the interpretation of basic terms, the lack of a clear state, public and scientific position on this issue. Such an approach with insignificancy to understanding the fundamental concepts that determine the development of a personality, leads to a misunderstanding of the mechanism of their impact on the personality, as well as the peculiarities of implementation in practice.

Thus, the analysis of the understanding of the essence of the concepts "spiritual and moral development", "spirituality", "morality" by the representatives of education, the media, state and municipal authorities allows us to conclude that, despite the increase in interest in this topic in recent years, up to now a unified understanding of their content, similarities and differences has not been developed, which leads to difficulties in their implementation in practice

The lack of understanding of the essence of spirituality and morality, as the basis for the spiritual and moral development of the individual and society, leads to a distortion of the content of the developed options for solving the problem, determining the criteria for checking changes in the development of the individual and society. This actualizes the task of defining the essence of the processes under study, identifying the mechanisms of formation in the Russian society of mass consciousness, focused on the spiritual and moral processes to ensure sustainable long-term innovative development of the country.

That is why, according to the experts, the problem of the spiritual and moral development and upbringing of a harmoniously developed personality should be a key task of the modern state policy of the Russian Federation and be addressed systematically and consistently at all levels of the state power. It is the state that should become the backbone of the spiritual and moral revival of Russian society, which is capable of organizing coordinated interaction of educational institutions, all subjects of socialization, the media to jointly ensure the conditions for the spiritual and moral development of the individual in Russian society.

\section{Conclusions}

For centuries, on the territory of Russia, the basis for the development of personality and society has been a traditional mentality with a basis in the form of the spiritual and moral meanings and values. An essential understanding of the content of spirituality and morality created the foundations for the spiritual and moral development of a young person and society as a whole. The 2009-2019 sociological survey allowed to determine the understanding by the experts of the concepts "spiritual and moral development", "spirituality" and "morality" by the representatives of education, the media, state and municipal authorities, as well as to analyze the process of the spiritual and moral development of the individual, social factors favorable to the spiritual and moral preparation of people for their life in a modern society.

The expert survey made it possible to reveal a low level of society's ability to the spiritual and moral development and to ensure the spiritual security of the individual, a distortion of the spiritual and moral guidelines for the development. The expert comprehension of the spiritual and moral state of Russian society revealed the reasons that cause the decline of spirituality and morality, showing their strategic importance in determining the nature and direction of the development of both a specific individual and the country as a whole. This has shaped the relevance of continuing the research, dictated by the complicated problem, a 
pronounced practical interest for the individual, society, the state and the value, and worldview potential that is fundamental for their development.

\section{References}

1. L.S. Perepelkin, Social theory issues, XII, 172-186 (2020) DOI: 10.30936/2227-79512020-12-172-186

2. Y.M. Reznik, Social theory issues, XII, 10-25 (2020) DOI: 10.30936/2227-79512020-12-10-120

3. A.V. Lubsky, et al, Mental programs and models of social behavior in the Russian society. Monograph (Rostov-on-Don: Science and Education Foundation, 2016)

4. A.V. Lubsky, R.A. Lubsky, V.P. Voitenko, , Humanities in the South of Russia 6, 3, 225-239 (2017) DOI: 10.23683/2227-8656.2017.3.20

5. E.I. Titova, The essence and originality of the manifestation of the economic mentality of the Russian person. Manuscript . Tambov: Gramota, 12, 9, 130-133

(2019) DOI : 10.30853/manuscript.2019.9.27

6. V.V. Babashkin, Mir Rossii, 27, 4, 163-175 (2018) DOI: 10.17323/1811-038X-201827-4-163-175

7. Yu.V. Verba, Philosophical Anthropology, 3, 1, 135-150 (2017) DOI: 10.21146/24143715-2017-3-1-135-150

8. D.B. Kazantseva, Self-actualization of spiritual and moral potential of personality in Russia. Monograph (Prague: Vědecko vydavatelské centrum «Sociosféra-CZ», 2020)

9. D.B. Kazantseva, E.K. Klimova, T.E. Chernysheva, Humanities: urgent problems of humanities and education, 20, 2, 174-188 (2020) DOI:10.15507/20789823.050.020.202002.174-189

10. A.R. Bulatova, History of philosophy, 22, 1, 121-135 (2017) DOI: 10.21146/20745869-2017-22-1-121-135

11. O.Y. Glukhova, Social theory issues, X, 53-58 (2018) DOI: 10.30936/2227-79512018-10-53-58

12. A.V. Guschina, Samara Scientific Bulletin, 8, 3 (28), 270-275 (2019) DOI 10.24411/2309-4370-2019-13306

13. E.Y. Pochtareva, Perm University Bulletin, 4, 563-575 (2017) DOI:10.17072/20787898/2017-4-563-575

14. L. Sagiv, S. Roccas, J. Cieciuch, S.H. Schwartz, Nature Human Behaviour, 1(9), 630639 (2017) DOI: 10.1038/s41562-017-0185-3

15. M.S. Yanitsky, Bulletin of Kemerovo State University, 22(1), 194-206 (2020) DOI:10.21603/2078-8975-2020-22-1-194-206

16. D.B. Kazantseva, Transformational Processes of the Spiritual Potential of a Personality (Monograph. Penza: PSU Publishing House, 2010) 